\title{
Analisis Response Time Penatalaksanaan Rujukan Kegawatdaruratan Obstetri Ibu Hamil
}

\author{
Response Time Analysis of Management Obstetric Maternal \\ Emergency Referral
}

\author{
Dwi Ayu Tirtaningrum*, Ayun Sriatmi, Antono Suryoputro \\ Bagian Administrasi dan Kebijakan Kesehatan, Fakultas Kesehatan Masyarakat \\ Universitas Diponegoro \\ (*dwiayutirtaningrum261@gmail.com)
}

\begin{abstract}
ABSTRAK
Pemerintah Kota Semarang membentuk puskesmas PONED dan rumah sakit PONEK untuk sistem rujukan dalam pengelolaan kasus obstetri. Faktanya, response time rujukan masih dirasakan lama oleh pasien untuk mendapatkan pelayanan. Tujuan penelitian menganalisis response time penatalaksanaan rujukan kegawatdaruratan obstetri ibu hamil di Kota Semarang. Jenis penelitian survei dengan pendekatan deskriptif kualitatif dan teknik purposive. Pengumpulan data menggunakan wawancara mendalam, dokumentasi, dan triangulasi sumber. Hasilnya response time pelaksanaan dan penerimaan rujukan belum optimal seperti harapan pasien. Lama waktu dari pasien datang di IGD Puskesmas PONED hingga siap dirujuk ke RS PONEK rata-rata 1-2 jam. Lama waktu penerimaan pasien datang di IGD RS PONEK hingga mendapatkan kamar perawatan 2 -3 jam. Lama waktu disebabkan kesiapsiagaan tim medis yang kurang tanggap merespon pasien, ibu hamil tidak membawa buku KIA dan tidak melengkapi persyaratan administrasi, sopir ambulans sulit dihubungi, konfirmasi pemberian informasi dari RS rujukan dan lamanya proses pemindahan pasien dari ruang bersalin ke kamar perawatan.
\end{abstract}

Kata kunci : Response time, proses kegawatdaruratan obstetri

\section{ABSTRACT}

Semarang government established PONED Health Center and PONEK Hospital for referral in managing obstetric cases. In fact, response time referral is still long to get the service by patients. Research purposes, analyze of response time in the management obstetric maternal emergency referral in Semarang. Type of survey research with qualitative descriptive approach and purposive technique. Data collection using indepth interviews, documentation, and source triangulation. The results, response time implementation and acceptance of referral has not been optimal as patient expectation. Length of time the patient came to the emergency room of Health Center until ready referred to the PONEK Hospital 1-2 hours. Length of time the patient receives at the emergency room of PONEK Hospital until get treatment room 2-3 hours. The problem because responsiveness of the medical team responding to patients, maternal not carrying $M C H$ books and not completing administrative, ambulance driver difficult to contact, confirmation of information from referral hospital and duration of patients transfer process from delivery room to treatment room.

Keywords : Response time, obstetrics emergency process 


\section{PENDAHULUAN}

Masalah kesehatan di Indonesia yang masih menjadi perhatian khusus, yaitu tingginya Angka Kematian Ibu (AKI). Tingkat kematian ibu yang tinggi dapat menyangkut kehormatan dan harga diri bangsa Indonesia. Kota Semarang menduduki rangking ke-3 dengan kasus kematian ibu yang tinggi di Jawa Tengah tahun 2016 setelah Kabupaten Brebes dan Pemalang, dengan 121,50/100.000 kelahiran hidup. ${ }^{1}$ Hal tersebut sedikit menurun dibanding AKI tahun 2015 sebesar 128,05/100.000 kelahiran hidup, dan belum mencapai target MDGs. ${ }^{2}$

Kasus kematian ibu di Kota Semarang tahun 2016 disebabkan oleh komplikasi penyakit penyerta diantaranya tumor otak, kanker tulang, kanker getah bening, TB, kanker mamae dan AIDS sebesar $51 \%$, pre-eklampsia berat $21 \%$, perdarahan $12 \%$, sepsis $6 \%$ dan penyebab lain-lain diantaranya syok, neurogenik, unidentified factors $(9,4 \%)$. Berdasarkan tempat terjadinya, kematian ibu terbanyak meninggal di rumah sakit sebesar $84,37 \%$, meninggal dalam perjalanan (death of arrival) sebesar 9,3\%, dan di rumah 6,25\%. ${ }^{1}$

Dalam Permenkes No.1 Tahun 2012 tentang Sistem Rujukan Pelayanan Kesehatan Perorangan, dijelaskan layanan rujukan mengacu prinsip kecepatan dan ketepatan tindakan, efisien, efektif sesuai dengan kemampuan dan kewenangan petugas kesehatan serta fasilitas pelayanan kesehatan. ${ }^{3}$ Dengan demikian, dalam layanan rujukan obstetric emergency harus memenuhi kriteria tersebut.

Informasi dari Puskesmas PONED di Kota Semarang diketahui total pasien yang berkunjung dalam layanan obstetri di Puskesmas PONED di Kota Semarang tahun 2014 s/d Maret 2017 sebanyak 2.630 orang. Dari jumlah tersebut yang dirujuk karena mengalami kegawatdaruratan obstetri sebanyak 1.127 orang $(42,8 \%)$. Rujukan Puskesmas PONED untuk area Semarang Timur ke RSUD K.R.M.T Wongsonegoro sedangkan untuk area Semarang Barat ke RSUD Tugurejo. Jenis komplikasi persalinan terbanyak dirujuk, yaitu Ketuban Pecah Dini (KPD) dan Pre-Eklampsia (PE). ${ }^{4}$

Penelitian Ignasius menjelaskan bahwa pertimbangan utama memilih tempat rujukan dari puskesmas ke rumah sakit sebagai penyedia layanan kesehatan sekunder adalah faktor kedekat- an jarak dan kemudahan jangkauan. Alur rujukan selama ini belum sepenuhnya memperhatikan aspek ketersediaan dan kelengkapan jenis layanan pada fasilitas kesehatan yang dituju. Selain itu, masih ada stigma bahwa jika puskesmas tidak bisa menangani masalah pasien maka rumah sakit menjadi pihak yang dianggap bisa menyelesaikan masalah tersebut. Sementara lainnya, rumah sakit di daerah belum tentu memiliki kapasitas dalam menangani masalah tersebut. Adapun implementasi suatu sistem tidak akan berjalan baik jika pelaksanaannya tidak sesuai dengan ketentuan kebijakan atau pedomannya. Salah satu problem dalam implementasi sistem rujukan adalah keterbatasan sumber daya dan infrastuktur yang esensial dalam institusi kesehatan untuk menyediakan layanan kesehatan yang minimal. ${ }^{5}$

Keterbatasan sumberdaya yang dimiliki puskesmas dan adanya berbagai permasalahan yang harus dihadapi oleh puskesmas, diperlukan keterpaduan dengan berbagai sektor untuk menunjang dan memaksimalkan pelaksanaan puskesmas salah satunya, yaitu melakukan rujukan ke PPK lain untuk membantu menyelesaikan permasalahan yang dialami oleh masyarakat serta meningkatkan efisiensi. ${ }^{6}$

Alasan utama memilih kedua RS tersebut karena lokasi yang lebih dekat dan faktor biaya yang lebih terjangkau. Dengan banyaknya pasien rujukan obstetri yang datang di kedua rumah sakit tersebut menjadikan pelayanan kurang maksimal. Hasil observasi diketahui bahwa kesiapsiagaan tim medis di puskesmas maupun di rumah sakit belum berjalan optimal dalam memberikan layanan (tindakan) kepada pasien, kesiapan sumber daya yang masih kurang dan lama waktu proses rujukan yang dirasakan masih lama oleh ibu hamil kagawatdaruratan obstetri, yaitu seperti ibu hamil yang tidak membawa buku KIA yang dapat memperlambat waktu pemeriksaan klinis, sopir ambulance yang tidak ada di tempat saat proses rujukan, lama waktu observasi di Instalasi Gawat Darurat (IGD) dan kelambanan pemberian informasi kamar kosong untuk rawat inap rujukan. Response time dalam pelaksanaan rujukan yang cenderung lamban ditakutkan berpotensi dapat membahayakan keselamatan ibu hamil.Response time dalam proses rujukan harus berdasarkan SOP (Standard Operate Procedure) yang beraku di puskesmas 
PONED dan rumah sakit PONEK. Berdasarkan latar belakang tersebut peneliti tertarik menganalisis response time penatalaksanaan rujukan kegawatdaruratan obstetri ibu hamil dari puskesmas PONED ke rumah sakit PONEK di Kota Semarang dilihat dari kesiapan tim medis, sumberdaya dan lama waktunya.

\section{BAHAN DAN METODE}

Jenis penelitian survei dengan pendekatan deskriptif kualitatif. Subyek penelitian yang diambil menggunakan teknik purposive berdasarkan kasus rujukan. Informan utama sebanyak 8 orang dengan kasus Ketuban Pecah Dini, Persalinan Macet, Pre-eklampsia Berat, Partus Tak Maju, Serotinus, Partus Prematurus Imminens, Anemia dan Perdarahan. Informan triangulasi sebanyak 8 orang meliputi Bidan Puskesmas PONED (6 orang) dan Ketua Tim PONEK Rumah Sakit (2 orang). Pengumpulan data dengan wawancara mendalam, dokumentasi, triangulasi, yang hasilnya dianalisis menggunakan analisis isi (content analysis).

\section{HASIL}

Penelitian dilakukan pada ibu hamil kasus obstetri sebanyak 8 orang. Usia ibu hamil berkisar $17 \mathrm{~s} / \mathrm{d} 38$ tahun dengan latar belakang pendidikan terakhir SD sebanyak 4 orang dan 4 orang SMA/SMK. Mayoritas pekerjaan yaitu ibu rumah tangga dan 2 orang karyawan swasta. Pengeluaran rata-rata $\pm \mathrm{Rp} 71.000$ per keluarga per hari. Riwayat penyakit ada 2 orang ibu hamil kasus KPD dengan hepatitis dan Pre-Eklampsia Berat dengan hipertensi tinggi. Paritas berkisar 1-3 orang anak. Usia kehamilan dari umur 24-42 minggu. Seluruh informan utama tidak memiliki riwayat persalinan seperti sectio caecar.

Menurut UU No.4 Tahun 2009 kesiapsiagaan tim medis di Puskesmas PONED sesuai dengan standar waktu yang dibutuhkan untuk memberikan penanganan pada ibu hamil di IGD PONED adalah sekitar $\leq 5$ menit. ${ }^{7}$ Namun demikian, ada kasus persalinan macet ibu hamil mengatakan response time yang diterima cukup lama yaitu $>10$ menit dikarenakan pintu ruang IGD dikunci malam hari. Itu pun ditambah ada perdebatan antara bidan dengan keluarga pasien karena marah dibangunkan dan membutuhkan waktu lagi untuk ibu hamil mendapatkan penanganan. Beri- kut kutipan yang diungkapkan oleh ibu hamil kasuspersalinan macet:

"kira-kira jam 1 malam, jadi pintu IGDnya dikunci terus bapak saya panggil-panggil bidannya gaknyautin ternyata tidur. Ya kira-kira kurang lebih 10 menitan lah baru dibukain pintunya terus setelah dibangunkan bidannya marah berkelahi dengan bapak saya karena tidurnya diganggu”.

Pada kesediaan sumberdaya rata-rata petugas kesehatan dan sopir ambulans yang dibutuhkan masih belum sesuai yang diharapkan. Namun, hal tersebut beberapa bisa diupayakan agar pengiriman pasien rujukan tepat waktu dengan sumber daya yang terbatas. Pada proses rujukan rata-rata sopir dan mobil ambulans sudah standby di tempat. Namun demikian, kasus persalinan macet dan anemia, sopir ambulans sulit dihubungi saat proses rujukan serta pada kasus partus tak maju masih menunggu Ambulans Hebat dan sopirnya. Lama waktu yang dibutuhkan untuk menunggu sopir dan Ambulans Hebat di ketiga puskesmas tersebut kurang lebih 30 menit untuk bisa segera dikirim ke rumah sakit rujukan.

Menurut informasi dari bidan di puskesmas PONED rata-rata lama waktu pasien datang di puskesmas PONED hingga pasien siap dirujuk ke RS sesuai dengan SOP yang berlaku membutuhkan waktu kurang dari 1 jam untuk kasus kegawatdaruratan obstetri. Namun faktanya, lama waktu yang dibutuhkan berkisar 1-2 jam hingga pasien siap dirujuk. Kendalanya, dikarenakan tim medis tidak merespon cepat pasien yang datang, ibu hamil tidak membawa buku KIA sehingga pemeriksaan klinis menjadi lama dan tidak membawa persyaratan administrasi, sopir ambulans sulit dihubungi dan konfirmasi pemberian informasi dari RS cenderung masih lama.

Lama waktu pemberian informasi rujukan sesuai SOP adalah 10-15 menit. Namun, faktanya dibutuhkan waktu rata-rata lebih dari 10-15 menit bahkan pernah hingga sampai 1 jam dan keesokan harinya melalui Jejaring Rujukan Maternal dan Neonatal (SIJARIEMAS). Dengan demikian, bidan mengungkapkan sudah jarang menggunakan SIJARIEMAS karena responnya dianggap lamban dalam pemberian konfirmasi sehingga 
alternatifnya langsung menghubungi rumah sakit rujukan. Namun, hal tersebut juga pernah direspon lama oleh rumah sakit rujukan selama 1 jam dalam memberikan konfirmasi.

Berikut kutipan yang diungkapkan oleh Tim IGD PONED:

\section{“..biasanya konfirmasi dari rumah sakit menunggu 15 menit terus menelpon lagi tetapi kadang sudah gitu penuh tetapi per- nah sampai lama 1 jam nunggunya kon- firmasi dari RS. Kadang kita masih pakai SIJARIEMAS kadang juga tidak jadi kita kerjain dua-duanya biar sama-sama jalan. Karena SIJARIEMAS pernah hingga ke- esokan harinya baru konfirmasi jadi kami takut kalau hanya mengandalkan sistem SIJARIEMAS..."(IT-3)}

Lama waktu di perjalanan juga menentukan keselamatan dan keamanan ibu dan bayi baru lahir. Pada kelompok puskesmas area Semarang Timur umumnya merujuk ke RSUD K.R.M.T Wongsonegoro. Sedangkan, puskesmas PONED area Semarang Barat ke RSUD Tugurejo. Lama waktu yang dibutuhkan proses rujukan di perjalanan berkisar \pm 20-30 menit meskipun dalam kondisi macet.

Pada kesiapsiagaan tim medis di rumah sakit PONEK beberapa sudah direspon cepat ketika pasien datang di IGD PONEK yaitu $\leq 5$ menit. Namun, beberapa pasien kasus persalinan macet dan serotinus yang tidak didahulukan dan menunggu hingga 30 menit baru ditangani oleh petugas kesehatan. Setelah dikonfirmasi, bahwa pasien tidak didahulukan dikarenakan belum terlalu kritis kondisinya dan saat itu terjadi lonjakan pasien sehingga belum menangani secara maksimal karena kuantitas sumberdayanya juga masih terbatas.

Ketersediaan Dokter Spesialis Obgyn ratarata ketika pasien datang sudah cepat mendapatkan penanganan. Namun, beberapa ibu hamil kasus persalinan macet, pre-eklampsia berat, dan anemia harus menunggu sekitar 30 menit-1 jam. Penyebabnya dikarenakan ruang jaganya tidak di ruang IGD melainkan di ruang khusus di Very Important Person (VIP). Pasien juga mengatakan bahwa perilaku dari Dokter Spesialis Obgyn juga cenderung kurang tanggap dan empatik dalam menindaklanjuti pasien.
Selain itu, ibu hamil kasus partus tidak maju juga tidak dilayani oleh Dokter Spesialis Obgyn seharusnya dikertas form dilakukan tindakan medis oleh Dokter X, tetapi faktanya tidak berkunjung ke pasien yang bersangkutan dari awal pemeriksaan hingga akhir dirawat inap di RS. Setelah dikonfirmasi, bahwa mungkin saat itu Dokter X tidak mengenakan jas putih kedokteran sehingga pasien mengira Dokter X bukan seorang dokter.

Informasi dari Tim PONEK rata-rata lama waktu penerimaan ibu hamil dari datang di IGD PONEK hingga mendapatkan kamar rawat inap bersalin sesuai standar SOP adalah 1 jam 30 menit untuk pasien rujukan kegawatdaruratan osbtetri. Namun, faktanya di lapangan membutuhkan lama waktu hingga 2-3 jam. Kendalanya, pada kesiapsiagaan tim medis belum merespon cepat ketika pasien datang dan persiapan kamar rawat inap yang masih lama. Lama waktu yang dibutuhkan untuk pasien di pindahkan ke kamar perawatan membutuhkan waktu \pm 30 menit -1 jam. Hal ini pun membuat ibu hamil menjadi gelisah dan kurang nyaman. Setelah dikonfirmasi, adanya lama waktu tersebut dikarenakan petugas rawat inap harus mempersiapkan terlebih dahulu kamar, kasur, perlengkapan ibu dan bayinya serta obat-obatan yang dibutuhkan untuk ibu dan bayi di ruang perawatan.

Berikut kutipan yang diungkapkan oleh TimIGD PONEK :

“...jadi bisa 1 jam atau 2 jam dan tergantung kamar juga kosong atau tidak. Jadi memang tidak segampang itu untuk cari kamar kosongnya. Jadi harus dipersiapkan terlebih dahulu kasur dan perlengkapan yang dibutuhkan ibu hamil dan bayinya.." (ITRS-1)

\section{PEMBAHASAN}

Kecepatan dan ketepatan proses rujukan pasien dari puskesmas PONED menuju ke rumah sakit PONEK harus sesuai dengan kompetensi dan standar pelayanan sehingga penanganan yang diberikan berdasarkan SOP yang berlaku dapat cepat dan ditindak dengan tepat. Ada beberapa hal yang harus diperhatikan dalam rujukan, yaitu salah satunya kesiapsiagaan tim medis yang jaga di IGD kepada pasien yang datang di puskesmas 
PONED. Pada kesiapsiagaan di IGD PONED diketahui belum sesuai standar yaitu $\leq 5$ menit dan tidak menanggapi serius atas kasus yang dialami oleh ibu hamil yang mengalami kritis dan butuh pertolongan pertama. Menurut penelitian Asmawi dan Amiruddin, pentingnya kompetensi (pengetahuan, sikap dan keterampilan) untuk menunjang kinerja dalam melakukan triase gawat darurat, tetapi nyatanya tidak ada hubungan pengetahuan dan sikap terhadap kinerja tim medis di IGD sedangkan keterampilan memiliki hubungan dengan kinerja tim medis. ${ }^{8}$ Sehingga dalam hal ini perlunya keterampilan tim medis dalam menjalankan tugas profesinya dengan baik karena sebagai orang yang dianggap berperan penting dalam menolong nyawa pasien, tetapi tidak hanya keterampilan saja seharusnya tim medis mempunyai sifat empati, cepat tanggap dan serius dalam menangani kasus pada pasien. Agar nyawa pasien dapat tertangani dengan optimal.

Selain dari kinerja petugas medis proses rujukan juga tidak akan berlangsung lancar tanpa adanya petugas sopir ambulans. Dalam penelitian ini beberapa petugas sopir ambulans sulit dihubungi dan terlambat datang sehingga dapat menghambat proses rujukan, seperti yang dikatakan oleh Zaharudin dkk dalam Nasution (2013), bahwa tingkat risiko kematian seorang pasien sangat bergantung pada waktu respon ambulans terhadap permintaan layanan ambulans. ${ }^{9} \mathrm{Hal}$ ini sebisa mungkin perlu dilakukan evaluasi terhadap kinerja petugas medis dan petugas sopir puskesmas serta perlunya penjelasan tentang kontrak kerja yang sudah ada karena sudah menjadi tanggung jawab pekerjaannya. Puskesmas pun jika merasa masih kekurangan sopir ambulans perlu penambahan sopir untuk bisa pergantian jam kerja. Jika tidak ditindaklanjuti secara cermat ditakutkan berpotensi membahayakan keselamatan pasien karena tidak segera dikirim ke rumah sakit rujukan.

Lama waktu rujukan akan menentukan keselamatan pasien. Lama waktu dari pasien datang di puskesmas PONED hingga pasien siap dirujuk ke rumah sakit membutuhkan waktu rata-rata 1-2 jam. Dalam hal ini, lama waktu yang dibutuhkan masih cenderung lama hingga 2 jam yang seharusnya bisa diminimalisasi menjadi kurang dari 1 jam. Hal ini perlu dievaluasi pada ibu hamil yang datang ke puskesmas harus membawa buku KIA dan persiapan administrasinya serta pihak puskesmas harus mempersiapkan segala sesuatunya yang dibutuhkan untuk rujukan dengan cepat dan tepat. Seperti yang dikatakan oleh Maatilu, V, bahwa persiapan dalam proses rujukan menentukan keberhasilan keselamatan pada pasien. ${ }^{10}$ Menurut penelitian Umaternate $\mathrm{T}$, mengemukakan bahwa ibu hamil yang mengalami sakit persalinan psikologisnya mudah berubah menjadi, cemas, kesakitan, takut dan sensitif sehingga ingin mendapatkan penanganan intensif segera. ${ }^{11}$

Proses rujukan di perjalanan diupayakan harus cepat dan aman untuk mencapai tempat rujukan. Agar nantinya ibu hamil pada kondisi gawat darurat cepat mendapatkan penanganan yang intensif. Lama waktu di perjalanan menentukan keselamatan dan keamanan ibu dan bayi baru lahir. Lama waktu yang dibutuhkan di perjalanan berkisar \pm 20-30 menit. Jika kondisi perjalanan macet masih dalam kisaran waktu tersebut karena ambulans menggunakan sirene sehingga perjalanannya masih tetap lancar. Ketepatan lama waktu perjalanan proses rujukan masih aman karena sesuai standar proses rujukan, yaitu paling lama 1 jam di perjalanan.

Penanganan gawat darurat di Instalasi Gawat Daurat (IGD) rumah sakit mempunyai filosofi, yaitu Time Saving it's Live Saving bisa diartikan waktu adalah nyawa atau seluruh tindakan yang dilakukan pada saat kondisi gawat darurat haruslah benar-benar efektif dan efisien. Hal ini mengingatkan pada kondisi tersebut pasien dapat kehilangan nyawa hanya dalam hitungan menit saja. Berhenti nafas 2-3 menit pada manusia dapat mengakibatkan kematian yang fatal. ${ }^{8}$

Pada pasal 1 UU RI No. 44 tahun 2009 tentang Rumah Sakit bahwa pasien yang masuk ke IGD butuh pertolongan cepat dan tepat. Oleh karena itu, perlu adanya standar dalam memberikan pelayanan gawat darurat sesuai dengan kompetensi dan kemampuannya. Semua itu dapat dicapai dengan meningkatkan sarana, prasarana, sumberdaya manusia dan manajemen IGD yang ada di rumah sakit. Pelayanan pasien gawat darurat adalah pelayanan yang memerlukan pertolongan segera dimana memegang peranan penting (time saving is life saving) bahwa waktu adalah nyawa. Capaian response time pelayanan IGD $\leq 5$ menit sesuai dalam Standar Pelayanan Minimal. ${ }^{7}$ 
Kebutuhkan akan response time (waktu tanggap) yang tepat dan efisien sangat berperan penting dalam setiap pengambilan keputusan mulai sejak awal pasien datang hingga pasien dipindahkan dari Instalasi Gawat darurat. Menurut Haryatun, N. dan Sudaryanto, A menyatakan bahwa response time (waktu tanggap) adalah kecepatan dalam penanganan pasien dihitung sejak pasien datang sampai dilakukan penanganan. Response time (waktu tanggap) pelayanan dapat dihitung dengan hitungan menit dan sangat dipengaruhi oleh berbagai hal, baik mengenai jumlah tenaga maupun komponen-komponen lain yang mendukung. ${ }^{12}$ Response time juga di kategorikan dengan prioritas $\mathrm{P} 1$ pasien gawat darurat dengan penanganan 0 menit, $\mathrm{P} 2$ pasien gawat dengan penanganan $<30$ menit dengan meningkatkan sarana dan prasarana sumber daya manusia dan manajemen IGD rumah sakit sesuai standar. ${ }^{13}$

Kesiapsiagaan tim medis pada ibu hamil kasus persalinan macet dan serotinus yang tidak didahulukan dan menunggu hingga 30 menit baru ditangani oleh petugas kesehatan. Setelah dikonfirmasi, alasan pasien tidak didahulukan karena pasien belum kritis kondisinya dan hal tersebut terkait sistem triage karena ada pasien lain yang lebih kritis kondisinya. Selain itu, kuantitas tim medis di IGD PONEK juga masih kurang jika terjadi lonjakan pasien. Dalam hal ini, seharusnya ketika di IGD jika kedatangan banyak pasien dalam waktu bersamaan, triage dapat menentukan pasien mana akan diberikan pertolongan segera. Bahkan saat sepi, triage tetap digunakan untuk menentukan waiting time pasien sesuai kondisinya. Oleh karena itu, dengan mengetahui prinsip kerja triage, seorang pasien dapat memaklumi. Pasien pun tidak perlu merasa dinomor duakan. Petugas ke- sehatan juga harus memberikan pemahaman kepada pasien dan keluarga sehingga tidak terjadi kesalahpahaman, seperti yang dikatakan Septiani, A bahwa petugas medis perlu memberikan informasi dan pemahaman kepada pasien dan keluarga agar tercapai tingkat kepuasan pada pelayanan medis yag diberikan. ${ }^{14}$ Oleh karena itu, karena terkadang pasien yang sedang mengalami sakit psikologisnya menjadi lebih sensitif, cemburu dan mudah marah karena tidak segera dilayani. Oleh karena itu, diupayakan tim medis di IGD melakukan tindakan kepada pasien gawat darurat secara cepat dan optimal.

Pada kesediaan Dokter Spesialis Obgyn ibu hamil menunggu berkisar 30 menit-1 jam untuk mendapatkan penanganan. Hal ini harus dievaluasi dan dilakukan perubahan dalam diri seorang penyelamat nyawa manusia, yaitu tanggap, mempunyai rasa empati dan tanggung jawab tinggi atas profesinya. Faktor jarak yang jauh antara ruang jaga Dokter Spesialis Obgyn dengan ruang IGD juga dapat mempengaruhi kecepatan dalam suatu tindakan medis. Oleh karena itu, jarak antara IGD dan ruang jaga Dokter Spesialis Obgyn bisa didekatkan karena kecepatan dan ketepatan berdampak pada keselamatan dan keamanan pasien. Kasus lain pada partus tak maju ibu hamil tidak dilayani Dokter Spesialis Obgyn yang seharusnya dikertas form dilakukan tindakan medis oleh Dokter X. Namun, faktanya tidak berkunjung ke pasien yang bersangkutan dari awal pemeriksaan hingga akhir dirawat inap di RS. Dalam hal ini, kegunaan jas dokter sebagai identitas kedokteran sehingga dokter mudah dikenali oleh pasien. Penting seorang dokter mengenakan jas putih sebagai identitas kedokteran sehingga pasien tidak perlu menanyakan apakah ia seorang dokter atau bukan. Selain itu, jas dokter bisa membuat psikologis jiwa pasien menjadi lebih baik karena ada rasa ketenangan untuk diobati oleh seseorang yang dianggap bisa menyembuhkan masalah kesehatannya dengan baik.

Rata-rata lama waktu penerimaan ibu hamil dari datang di IGD PONEK hingga mendapatkan kamar rawat inap bersalin berdasarkan SOP adalah 1 jam 30 menit untuk pasien rujukan kegawatdaruratan osbtetri. Namun, faktanya membutuhkan lama waktu hingga 2-3 jam. Kendalanya, pada kesiapsiagaan tim medis yang belum merespon cepat dan lama waktu persiapan kamar rawat inap. Hal ini perlu dievaluasi oleh RS agar melakukan tugasnya dengan cepat dan mempunyai rasa empati sebagai penolong keselamatan nyawa pasien. Lama waktu menunggu kamar rawat inap bersalin seharusnya RS bisa mengupayakan persiapan yang dibutuhkan ibu hamil dan bayinya dengan tindakan yang cepat karena pasien yang sakit, mengalami perubahan psikologi yang terganggu, yaitu mudah marah atau sensitif dimana ingin mendapatkan pelayanan secepat mungkin dan tidak peduli alasan apapun. Oleh karena itu, pihak rumah sakit 
mengupayakan dapat memberikan pelayanan terbaiknya secara optimal dan menanggapi keluhan pasien. Agar nantinya timbul rasa puas dan keselamatan serta keamanan kepada pasien.

\section{KESIMPULAN DAN SARAN}

Penelitian ini menyimpulkan bahwa response time dalam proses rujukan pasien ibu hamil dari puskesmas PONED menuju rumah sakit PONEK belum memenuhi standar SOP yang berlaku. Hal ini dilihat dari lama waktu dari ibu hamil datang di puskesmas PONED hingga siap dirujuk membutuhkan waktu rata-rata 1-2 jam. Hal ini disebabkan oleh kesiapsiagaan tim medis belum merespon cepat, ibu hamil tidak membawa buku KIA dan kurang melengkapi persyaratan administrasi, sopir ambulans sulit dihubungi dan kelambanan konfirmasi pemberian informasi dari rumah sakit rujukan. Lama waktu proses rujukan di perjalanan \pm 20-30 menit. Jika kondisi perjalanan macet tetap berkisar waktu tersebut. Lama waktu dari pasien datang di rumah sakit PONEK hingga pasien di pindahkan ke ruang perawatan membutuhkan waktu 2-3 jam. Hal ini disebabkan kesiapsiagaan tim medis belum merespon cepat ketika pasien datang dan persiapan kamar rawat inap.

Saran kepada ibu hamil yang datang ke puskesmas membawa buku KIA, kartu jaminan kesehatan, KTP, KK, surat nikah, uang dan didampingi keluarga. Kepada puskesmas menjelaskan kontrak kerja dengan sebaik-baiknya kepada sopir ambulans dan meningkatkan koordinasi dengan rumah sakit rujukan. Kepada rumah sakit jarak ruang IGD PONEK dan ruang jaga Dokter Spesialis Obgyn diharapkan bisa didekatkan serta tim medis di IGD PONEK diupayakan $\leq 5$ menit. Mengoptimalkan penggunaan sistem berbasis komputer dalam pencarian kamar kosong rawat inap serta mempersiapkan ruang perawatan beserta perlengkapan yang dibutuhkan dengan cepat. Diharapkan emergency service online $1 \mathrm{kali}$ dering telpon bisa langsung diangkat dan diberi jawaban tanpa perujuk harus menunggu kepastian. Kepada Dinas Kesehatan Kota Semarang diharapkan SIJARIEMAS kualitasnya ditingkatkan dengan konfirmasi yang cepat dan lancar antara perujuk dengan penyedia layanan rujukan.

\section{DAFTAR PUSTAKA}

1. Dinas Kesehatan Kota Semarang. Profil Kesehatan Kota Semarang Tahun 2016. Semarang: Dinas Kesehatan Kota Semarang. 2017.

2. Dinas Kesehatan Kota Semarang. Profil Kesehatan Kota Semarang Tahun 2015. Semarang: Dinas Kesehatan Kota Semarang. 2016.

3. Peraturan Menteri Kesehatan Republik Indonesia Nomor 1 Tahun 2012 Tentang Sistem Rujukan Pelayanan Kesehatan Perorangan. Jakarta: Kementerian Kesehatan RI. 2012.

4. Puskesmas PONED Kota Semarang. Buku Register Pasien Rawat Inap Tahun 2014 Maret 2017. Semarang: Puskesmas PONED Kota Semarang. 2017.

5. Luti, I., Hasanbasri, M. dan Lazuardi, L.Kebijakan Pemerintah Daerah dalam Meningkatkan Sistem Rujukan Kesehatan Daerah Kepulauan di Kabupaten Lingga Provinsi Kepulauan Riau. Jurnal Kebijakan Kesehatan Indonesia. 2012;1(1): 24-35.

6. Chabibah, N. dan Chalidyanto, D.Analisis Rasio Rujukan Puskesmas Berdasarkan Kemampuan Pelayanan Puskesmas. Jurnal Administrasi Kesehatan Indonesia.2014;2:159-168.

7. Undang-Undang Republik Indonesia No. 44 tahun 2009 Tentang Rumah Sakit. Jakarta: Presiden Republik Indonesia. 2009.

8. Asmawi, Hadju, V dan Amiruddin, R. Pengaruh Kompetensi terhadap Kinerja Perawat Instalasi Gawat Darurat dalam Melakuakan Triase di RSUD Kabupaten Majene. JST Kesehatan. 2017;7(4):389-394.

9. Nasution M.S. Model Untuk Keberangkatan dan Relokasi Fasilitas Ambulans [Tesis]. Medan: Universitas Sumatra Utara; 2013.

10. Maatilu, V. Faktor-Faktor yang Berhubungan dengan Response Time Perawat pada Penanganan Pasien Gawat Darurat di IGD RSUP Prof. DR. R.D. Kandous Manado. Jurnal Universitas Sumatera Barat [Online Journal] 2014 [diakses 12 Nopember 2017]. Dalam: http:// ejournal.unsrat.ac.id.

11. Umaternate, T. Hubungan Pelaksanaan Identifikasi Pasien Secara Benar dengan Kepuasan Pasien di Instalasi Gawat Darurat (IGD) RSUP Prof. DR. R.D. Kandou Manado. E-Jurnal Keperawatan. 2015;3(2):1-6.

12. Haryatun, N. dan Sudaryanto, A. Perbedaan 
Waktu Tanggap Tindakan Keperawatan Pasien Darurat RSUD Dr . Moewardi. Berita Ilmu Keperawatan. 2008;1(2):69-74.

13. Purba Dewi Efasusanti, Kumaat Lucky T dan Mulyadi. Hubungan Response Time dengan Kepuasan Keluarga Pasien Gawat Darurat Pada Triase Merah di IGD RSUP Prof. Dr. R.
D. Kandou Manado. Journal Keperawatan. 2015;3(2):1-7.

14. Septiani, A. Pengaruh Faktor - Faktor Kualitas Pelayanan Terhadap Kepuasan Pasien di Instalasi Gawat Darurat RSUD Kabupaten Sumedang. Jurnal Ilmiah Manajemen. 2016; $7(1): 1-21$. 